\title{
An Application of the Theory of Planned behavior (TBP) in describing Customers' Use of Cash Cards in Points of Sale (POS)
}

\author{
Mohammad Haghighi \\ Associate Professor, Faculty of Management, Tehran University, Tehran, Iran. \\ E-mail:mhaghighi@ut.ac.ir \\ Elnaz Rahrovy \\ (Corresponding Author) \\ MSc. student in MBA, Faculty of Management, Tehran University, Tehran, Iran \\ E-mail: Elnaz.Rahrovy@ut.ac.ir \\ Hadi Vaezi \\ MSc. student in MBA, Faculty of Management, Tehran University, Tehran, Iran \\ E-mail: hadivaezi@ut.ac.ir
}

Accepted: November 08, 2012 Published: December 27, 2012

Doi:10.5296/ijld.v2i6.2985 URL: http://dx.doi.org/10.5296/ijld.v2i6.2985

\begin{abstract}
This paper aims to investigate the use of cash cards in points of sale (POS), applying the theory of planned behavior. A field survey was conducted in Tehran, Iran. Data was collected and analyzed from 163 customers who have referred to chain stories in the area of Tehran. Findings indicate that the theory of planned behaviour is a suitable instrument to predict using cash cards by customers. In addition, multiple regression analysis revealed that attitude towards cash cards, subjective norms and perceived behavioural control have a positive and significant impact on intention to use cash cards by customers. Managers should consider various facets of customer decision-making process and try to enhance quality of provided payment services to satisfy customers.
\end{abstract}

Keywords: Cash card, Consumer behavior, Service quality, Tehran 


\section{Introduction}

Consumers significantly increased their use of cash and close substitutes for cash, such as money orders and prepaid cards. At the same time, consumers reduced their use of credit cards and (to a lesser extent) cash cards, as well as payments made using a bank account number (Foster et al., 2011). Weaker economic conditions, new government regulations, and bank pricing of payment card services all likely contributed to the shift back toward cash. However, it is difficult to determine how much each of these factors contributed, and whether the shift is transitory or permanent, without more data and research on consumer payment choice. In field studies, researchers have typically asked respondents directly about the degree of use of the cash cards in a survey of consumer payment choice (Foster et al., 2011). Fishbein and Ajzen (1975) report that under certain circumstances, intentions may be entirely unrelated to behaviour. More recently, Mittal and Kamakura (2001) find that variables influencing repurchase intentions are not related in the same way to repurchase behaviour. However, research shows that attitudes and behavioural intentions are not always good predictors for subsequent behaviour. On the other hand, as explained above, only analysing choice behaviour does not allow including other variables that typically influence choices as well. To see how perceived influences and behavior are interrelated, we need to first, investigate using cash cards by customers and second, measure the effectiveness of The theory of planned behavior (TPB) in describing customers' decision to buy with cash cards. TPB has been widely adopted as one of the most powerful tools to test consumers' behavioral intention (Ajzen, 2001). Thus, Ajzen's (1985, 1987, 1991) TPB has provided useful guidance for the current study. The paper is organized as follows. First, background information on cash card and a discussion of the TPB are provided. This discussion also includes an explication of the key components of the TPB, which leads to the development of hypothesis and research model. A research methodology is proposed. Finally, discussion and managerial implications will flow from verification of the model and its propositions.

\section{Conceptual background and hypothesis development}

\subsection{The theory of planned behavior (TPB)}

Ajzen's (1985, 1987, 1991) TPB model, described how behavior is formed. Ajzen (1985) extended roots from the Theory of Reasoned Action (TRA) and hypothesized three components underneath a person's behavioral intentions (Ajzen and Fishbein, 1980; Fishbein and Ajzen, 1975). He adopted two components from the TRA: an attitudinal component and a 
normative component. The TRA, which consists of only the attitudinal and normative components, was often criticized because it assumes that all human behaviors are volitional and rational (Chang, 1998); in other words, an individual has full control over his or her behavior. However, not all behaviors are fully volitional or fully controlled by consumers due to various factors (Sheppard et al., 1988). This is why the TPB adds a third component called perceived behavioral control (PBC) (Hansen et al., 2004). Many studies have confirmed that the TPB predicts behavior intention more accurately than the TRA (Madden et al., 1992; Taylor and Todd, 1995). A search of the major online data-bases revealed a large number of published studies in the social sciences using Ajzen's model. These studies address such areas as smoking behavior (Babrow et al., 1990), ethical behavior (Flannery \& May, 2000), risk-oriented behavior (Quinlan et al., 2006), or internet activity (Hsu \& Chiu, 2004). The overwhelming majority of these studies support the usefulness of Ajzen's theory and his view that behavioral intent is a powerful predictor of the targeted behavior. According to TPB, one's attitude towards a behavior, coupled with prevailing subjective norms, and with perceptions of behavioral control factors, all serve to influence an individual's intention to perform a given behavior (Ajzen, 1991). Applying TPB in the payment type choice, intention to use cash card is posited to influence an individual's subsequent behavior (use of cash card), while fully mediating the influences of attitudes and subjective norms on subsequent behavior (use of cash card). Moreover, perceived behavioral control also directly influences the intention to use cash cards in POS. In sum, this study investigates whether the TPB model can describe customers“ intention to use cash cards in POS. The research model derived from TPB is depicted as Figure 1. The research model excludes use of cash card, focusing on intention to use cash card as the dependent variable. TPB asserts that behavior, in this case, use of cash card is a direct function of intention to use cash card and that the intention to use cash card is jointly influenced by one's attitude toward using cash card, subjective norm, and perceived behavioral control. 


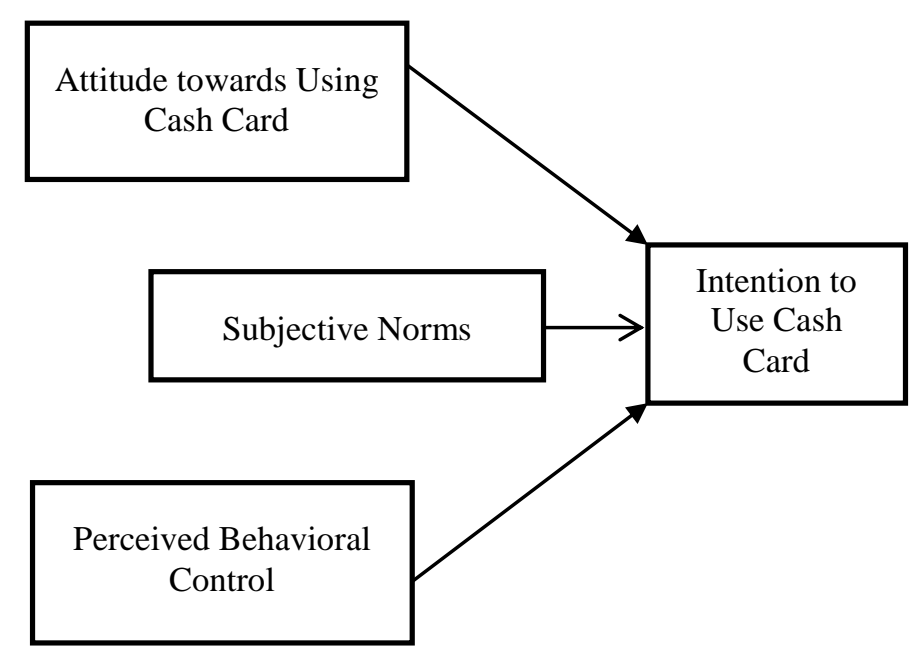

Figure 1. "Theory of planned behavior (TBP)"

\subsection{Attitude towards using cash cards}

Attitudes, which are relatively permanent and stable evaluative summaries about an item, are an important psychological construct because they have been found to influence and predict many behaviors (Kraus, 1995).The term "attitude" is categorized into a trio of affection, beliefs, and values, and cognition (Fishben \& Ajzen, 1972). In the affective aspect, the term "attitude" shows the individual's favorability to objects, events, or other persons (Ajzen, 1991; Fishben \& Ajzen, 1972). The cognitive aspect help individuals evaluate or judge situational conditions and consequences, such as the possibility or difficulty to implement one particular behavior (Ajzen, 1991; Bandura, 1977; Fishben \& Ajzen, 1972). Boundary of social norms and personal ability may transgress the individual's affections and cognitions and contribute to the final intention of making or not making a specific behavior (Ajzen, 1991). Moreover, beliefs and values are supposed to offer "cognitive and affective foundations" to the attitudinal determinants in identifying individuals' considerations of behavioral decisions (Ajzen, 2006, p.7). TPB defines attitude toward a behavior as "the degree to which a person has a favorable or unfavorable evaluation or appraisal of the behavior in question" (Ajzen, 1991, p. 188). In general, the more favorable the attitude toward the behavior, the stronger will be an individual's intention to perform the behavior (Ajzen, 1991). In our case, the target behavior is the intention to use cash card, and the attitude is that toward a using cash card. Attitude toward using cash card reflects feelings that performing a behavior would lead to a particular, and desirable, outcome, as a result of performing that behavior. Thus, it is hypothesized that:

$\mathrm{H}_{1}$ : There is a significant and positive relationship between attitudes toward using cash card and intentions to use cash cards in POS. 


\subsection{Subjective norm}

TPB postulates a second determinant of intention, subjective norm. Within TPB, subjective norm is defined as "the perceived social pressure to perform or not to perform the behavior" by the individual (Ajzen, 1991, p. 188). A component of subjective norm is normative belief, or the individual's perception of a significant referent other's opinion about the individual's performance of the behavior. TPB views the role of social pressure to be more important when the motivation to comply with that pressure is greater. Motivation to comply is the extent to which the person wants to comply with the wishes of the other party (Mathieson, 1991). The role of subjective norm as a determinant of intention is well documented in situations where the actual behavior entails tangible and beneficial consequences for the consumer (Taylor and Todd, 1995). Thus, it is hypothesized that:

$\mathrm{H}_{2}$ : There is a significant and positive relationship between subjective norm and intentions to use cash cards in POS.

\subsection{Perceived behavioral control}

Finally, Perceived behavioral control refers to (Ajzen, 1991, p. 188): "the perceived ease or difficulty of performing the behavior". Moreover, perceived behavioral control (p. 122) "is assumed to reflect past experience as well as anticipated impediments and consequences". According to TPB, it is the perception of behavioral control, as opposed to the degree of actual behavioral control that directly impacts both intentions to perform a behavior, as well as the actual performance of that behavior. Ajzen's view of perceived behavioral control is similar to Bandura's $(1977,1982)$ notion of perceived self-efficacy, which is "concerned with judgments of how well one can execute courses of action required to deal with prospective situations" (Bandura, 1982, p. 122). Bandura's research has demonstrated that people's behavior is strongly affected by their confidence in their ability to perform that behavior. When behaviors are perceived as challenging or there are barriers to performance, however, perceived behavioral control becomes a more important factor predicting behavior. Perceived behavioral control is comprised of two factors:

(1) control beliefs, which relate to the sense of the self-availability of skills, resources and opportunities; and

(2) perceived facilitation, which relates to an individual's assessment of the importance of those skills, resources and opportunities for the achievement of desired outcomes. 
Control beliefs can be situational as well as personal (Mathieson, 1991). Ajzen (2002) argues that perceived behavioral control is related to self-efficacy (Bandura, 1977) in that both reflect the perceived ability to perform a behavior. Within the context of buying behaviour, perceived behavioral control relates to the customer's perception of the satisfactory of chain store and to the opportunities for using cash cards in POS, and to an individual's self-confidence in his or her ability to use cash cards. Perceived behavioral control has been shown to be an important determinant of bahavioral intention. In a direct test, Mathieson (1991) found that perceived behavioral control did have a significant effect of behavioral intention. Thus, it is hypothesized that:

$\mathrm{H}_{3}$ : There is a significant and positive relationship between perceived behavioral control and intentions to use cash cards in POS.

\section{Methodology}

\subsection{Sampling}

To achieve research goal, a field survey design was used at Tehran, Iran. The target population was customers who referred to chain stores during a two-week period of research in Shahrivar 1390. A confidence interval approach was used to determine the sample size, suggested by Burns and Bush (1995). The sample size was set at 163 at the $95 \%$ confidence level (Burns \& Bush, 1995). We used cluster-sampling plan. Two stages of sampling approach were used in this study: First, we provided a list of chain stores in Tehran, and then a number of chain stores were selected randomly. Finally, customers who had referred to those stores, selected randomly to achieve estimated sample.

\subsection{Instrument}

A survey questionnaire was designed to measure the research model variable constructs. Each variable construct (e.g. attitude, subjective norms, perceived behavioral control, and intention) was measured using multiple items. The survey questionnaire consisted of three major sections. The first section contains the scale of TPB including attitude toward behavior, subjective norm, perceived behavioral control, and behavioral intention which adopted from Kassem and Lee's (2004) study and modified by the researcher and used 12 questions to measure these dimensions. A seven-point rating scale (from $1=$ extremely disagree to $7=$ extremely agree) was employed to measure the above determinants. The second section is about demographic characteristics of customers. This section concluded four items: age, gender, income, and education. Table I shows the demographic profile of the respondents. A 
pilot test was performed to assess how well the survey instrument captured the constructs it was supposed to measure, and to test the internal consistency and reliability of questionnaire items. The first draft of the survey instrument was distributed to 20 randomly selected customers who referred to Shahrvand chain stores, the largest chain stores among other chain stores in terms of number of customers' referrals. A total of 50 questionnaires were collected at the site. Cronbach's alpha was used to verify the internal consistency reliability. Cronbach's coefficients of behavioral intention, attitude, subjective norm, and perceived behavioral control were $0.82,0.76,0.83$, and 0.81 , respectively. The reliabilities of the different measures in the model range from 0.76 to 0.83 , which exceed the recommended threshold value of 0.70 (Nunnally, 1978). Based on the results of the pilot test, the final version was modified considering questionnaire design, wording, and measurement scale. We used Pearson correlation and multiple regression analysis to test hypotheses. The data was processed with the statistical software of SPSS 18.0.

\begin{tabular}{|lccc|}
\hline \multicolumn{4}{|c|}{ Table 1. Demographical characteristics of respondents } \\
\hline Characteristic & Frequency & Percentage & CF (\%) \\
\hline Age & 40 & 24.53 & 24.53 \\
Under 25 & 32 & 19.63 & 44.16 \\
$25-35$ & 44 & 26.99 & 71.15 \\
$35-45$ & 28 & 17.18 & 88.33 \\
$45-55$ & 19 & 11.66 & 100 \\
Upper than 55 & & & \\
Gender & 48 & 29.45 & 29.45 \\
Male & 115 & 70.55 & 100 \\
Female & & & \\
Income (*10/000 Rial) & 35 & 21.47 & 21.47 \\
300-500 & 63 & 38.65 & 60.12 \\
501-800 & 49 & 30.06 & 90.18 \\
801-1200 & 16 & 9.82 & 100 \\
More than 1200 & & & \\
Education & 24 & 14.72 & 14.72 \\
Primary or bellow & 48 & 29.44 & 44.16 \\
Secondary & 83 & 50.92 & 95.08 \\
University & 8 & 4.92 & 100 \\
Post-graduate & & & \\
\hline
\end{tabular}




\section{Data analysis and results}

The descriptive statistics and correlations for the multi-item constructs are shown in Table 2. Overall, these measurement results are satisfactory and suggest that it is appropriate to proceed with the evaluation of the structural model.

\begin{tabular}{|l|c|c|c|c|c|c|}
\hline Table 2. Descriptive statistics & Mean & SD & $\begin{array}{c}\text { Attitud } \\
\mathrm{e}\end{array}$ & $\begin{array}{c}\text { Subjectiv } \\
\text { e Norms }\end{array}$ & $\begin{array}{c}\text { Perceived } \\
\text { Behavioral } \\
\text { Control }\end{array}$ & $\begin{array}{c}\text { Behavioral } \\
\text { Intention }\end{array}$ \\
\hline Attitude & 5.105 & $\begin{array}{c}0.99 \\
8\end{array}$ & 1.00 & $0.578^{*}$ & $0.507^{*}$ & $0.651^{*}$ \\
\hline Subjective Norms & 5.097 & $\begin{array}{c}0.94 \\
2\end{array}$ & $0.578^{*}$ & 1.00 & $0.467 *$ & $0.639^{*}$ \\
\hline $\begin{array}{l}\text { Perceived Behavioral } \\
\text { Control }\end{array}$ & 5.164 & $\begin{array}{c}0.92 \\
1\end{array}$ & $0.507^{*}$ & $0.467^{*}$ & 1.00 & $0.633^{*}$ \\
\hline Behavioral Intention & 6.128 & $\begin{array}{c}0.56 \\
9\end{array}$ & $0.651^{*}$ & $0.639^{*}$ & $0.633^{*}$ & 1.00 \\
\hline
\end{tabular}

Table 3 presents results of a multiple regression analysis used to evaluate the strength of the proposed relationship. Three hypotheses were formulated and all the variables retain after testing the reliability. The individual hypotheses were tested using a multiple regression prediction model following the guidelines established by Hair et al. (1998) with cash card using intention as the dependent variable. The results obtained, as shown in Table 3, revealed that H1-H3, were found to be significant in the prediction model. The results provide support for hypotheses $\mathrm{H} 1-\mathrm{H} 3$, that is, the relationship between attitude toward cash cards $(\beta=0.213$ and $p=0.001)$, subjective norm on cash card using intention $(\beta=0.157$ and $p=0.01)$, and perceived behavioral control on cash card using $(\beta=0.205$ and $\mathrm{p}=0.001)$.

\begin{tabular}{|l|c|c|c|}
\hline \multicolumn{4}{|l|}{ Table 3. Regression results $(\mathrm{n}=163)$} \\
\hline Variables & $\beta$ & t-value & p-value \\
\hline Constant & 1.286 & 6.740 & $0.000^{* *}$ \\
\hline Attitude & 0.213 & 3.300 & $0.001^{* *}$ \\
\hline
\end{tabular}




\begin{tabular}{|l|c|c|c|}
\hline Subjective norms & 0.157 & 3.159 & $0.002 *$ \\
\hline Perceived behavioral control & 0.205 & 4.531 & $0.000^{* *}$ \\
\hline $\begin{array}{l}\text { Notes: Significance at: }{ }^{*} \mathrm{p} \leq 0.01 \text { and } * * \mathrm{p} \\
\text { 0.283; dependent variable: cash card using intention }\end{array}$ \\
\hline
\end{tabular}

\section{Discussion}

The main objective of this study is to explore how the TPB could facilitate in predicting the intention to use cash cards in POS of Iran's chain stores. The study results show that the TPB model could explain 29.1 percent of the variance in the intentions to use cash cards in POS. The model was statistically significant and this study results demonstrates, once again, the robustness of the TPB for helping to explain cash card using intention. Other studies have also successfully used the TPB as a theoretical framework from which to examine the purchase intention (Bredahl et al., 1998). The study depicted that attitude has a significant and positive effect on cash card using intention. Attitude is an important factor in influencing consumer intention in using cash card in POS because those with high positive attitudes appeared to have greater intentions to intent to use cash cards. Social pressure may compensate for high favorable attitudes in building intentions to use cash cards in such condition. Consistent to the study of Karijin et al. (2007), the research found that subjective norm was positively and significantly related to intention. This study also confirms other studies like Kamariah and Muslim's (2007) which found subjective norms to be important. In more individualistic cultures like Western cultures, people perceived themselves as autonomous and independent of the group and prioritized personal goals over collective goals, which would lead to a higher use of personal attitude versus social norms in behavioral decisions. On the other hand, in collectivistic cultures such as the Muslim culture, people tend to perceive themselves as interdependent with their group and tend to strive for in-group rather than personal goals (Karijin et al., 2007). This is matched with the findings of this study that subjective norm is important in influencing consumers' purchase intention, especially in Iran, a collectivistic country. The study also confirmed that perceived behavioral control has a significant effect on cash card using intention. The relationship is a positive relationship which means that the greater impact of control in explaining variability in behavior is not unusual. Eagly and Chaiken (1993) and Bonne and Verbeke (2006) summary studies concerning various behavioral criteria have reported similar findings. Ajzen (1991) suggested that control could directly affect behavior by increasing effort to goal achievement. 


\section{Implications and future research}

The TPB model appeared to effectively predict cash card using intention among consumers in Iran. To encourage cash card using in POS from a behavioral perspective, government authority and chain stores might focus on creating social expectations regarding cash card using and improving consumers' sense of their ability to use cash cards in POS. Past research may provide guidance in developing these perceptions, beliefs, and attitudes. As this research utilized a sample with a single country focus, we would like to suggest that future researchers examine the generalizability of these findings via cross-cultural studies. In addition, future studies of the influence of individual cognitive, social, demographic and cultural factors on intention to use cash cards as a type of payment in chain stores would provide researchers and practitioners alike with an advanced understanding of those unique individual and societal factors that predict intention to use cash cards.

\section{References}

Ajzen, I. \& Fishbein, M. (1980), Understanding Attitudes and Predicting Social Behavior, Prentice-Hall, Englewood Cliffs, NJ.

Ajzen, I. (2001), “Attitudes”, Annual Review of Psychology, Vol. 52, pp. 27-58.

Ajzen, I. (1985), "From intentions to actions: A theory of planned behavior", Inaction Control: From Cognition to Behavior, by Kauhl \& Beckman, (Eds.). Heidelberg: Springer, pp.11-39.

Ajzen, I. (1987). "Attitudes, traits, and actions: Dispositional prediction of behavior in personality and social psychology", Advances in Experimental Social Psychology, Vol. 20, pp.1-63.

Ajzen, I. (1991), "The theory of planned behavior", Organizational Behavior and Human Decision Process, Vol. 50 No. 2, pp. 179-211.

Ajzen, I. (2002), "Perceived behavioral control, self-efficacy, locus of control, and the theory of planned behavior", Journal of Applied Social Psychology, Vol. 32, No. 4, pp. 665-83.

Ajzen, I. (2006), "Constructing a TPB questionnaire: Conceptual and methodological considerations", Available at: http://www.people.umass.edu/ajzen/tpbrefs.html (19 August 2010).

Babrow, A.S., Black, D.R. and Tiffany, S.T. (1990), "Beliefs, attitudes, intentions, and asmoking-cessation program: a planned behavior analysis of communication campaigndevelopment", Health Communication, Vol. 2, pp. 145-63. 
Bandura, A. (1977), "Self-efficacy: toward a unifying theory of behavioral change", Psychological Review, Vol. 84 No. 2, pp. 191-215.

Bandura, A. (1982), "Self-efficacy mechanism in human agency", American Psychologist, Vol. 37 No. 2, pp. 122-47.

Bonne, K. and Verbeke, W. (2006), “Muslim consumer's attitude towards meat consumption in Belgium: insights from a means-end chain approach", Anthropology of Food, Vol. 5.

Bredahl, L., Grunet, K.G. and Frewer, I. (1998), “Consumer attitudes and decision-making with regard to genetically engineered food products - a review of the literature and a presentation models for future research", Journal of Consumer Policy, Vol. 21, pp. 251-77.

Burns, A. C., \& Bush, R. F. (1995), Marketing research. Prentice Hall, New Jersey.

Chang, M.K. (1998), "Predicting unethical behaviour: a comparison of the theory ofreasoned action and the theory of planned behaviour', Journal of Business Ethics, Vol. 17 No. 6, pp. 1825-34.

Eagly, A.H. and Chaiken, S. (1993), The Psychology of Attitude, Harcout Brace Jovanovich, Forth Worth, TX.

Fishben, M. \& Ajzen, I. (1972), “Attitudes and opinions”, Annual Review of Psychology, Vol. 23, pp. 487-544.

Fishbein, M. and Ajzen, I. (1975), Belief, Attitude, Intention, and Behavior: An Introduction toTheory and Research, Addison-Wesley, Reading, MA.

Flannery, B.L. and May, D.R. (2000), "Environmental ethical decision making in the US metal-finishing industry", Academy of Management Journal, Vol. 43, pp. 642-62.

Foster, K., Meijer, E., Schuh, S., and Zabek, M. A. (2001), “The 2009 Survey of Consumer Payment Choice", Public Policy, Working paper, No. 11-1, pp. 1-126.

Gruen, T. W., Osmonbekov, T., \& Czaplewski, A. J. (2005), eWOM: The impact of customer-to-customer online know-how exchange oncustomer value and loyalty. Journal of Business Research, Vol. 59 No. 4, pp. 449-456.

Hansen, T., Jensen, J.M. and Solgaard, H.S. (2004), "Predicting online grocery buying intention: acomparison of the theory of reasoned action and the theory of planned behaviour', International Journal of Information Management, Vol. 24, pp. 539-50.

Hsu, M.H. and Chiu, C.M. (2004), “Internet self-efficacy and electronic service acceptance”, Decision Support Systems, Vol. 38 No. 3, pp. 369-81. 
Kassem, N. O. \& Lee, J. W. (2004), “Understanding soft drink consumption among male adolescents using the theory of planned behavior", Journal of Behavioral Medicine, Vol. 27, pp. 273-296.

Kraus, S. J. (1995), “Attitudes and the prediction of behavior: a meta-analysis of the empirical literature", Personality and Social Psychology Bulletin, Vol. 21, pp. 58-75.

Karijin, B., Iris, V., Florence, B.B. and Wim, V. (2007), "Determinants of halal meat consumption in France", British Food Journal, Vol. 109 No. 5, pp. 367-86.

Kamariah, N. and Muslim, N. (2007), “The application of theory of planned behaviour (TPB) in internet purchasing: using SEM", International Conference on Marketing and Retailing, Petaling Jaya, pp. 196-205.

Madden, T.J., Ellen, P.S. and Ajzen, I. (1992), “A comparison of the theory of planned behavior andthe theory of reasoned action', Personality and Social Psychology Bulletin, Vol. 18 No. 1, pp. 3-9.

Mathieson, K. (1991), "Predicting user intentions: comparing the technology acceptance model with the theory of planned behavior", Information Systems Research, Vol. 2 No. 3, pp. 173-91.

Mittal, V. and Kamakura, W. (2001), "Satisfaction, repurchase intent, and repurchase behaviour :investigating the moderating effect of customer characteristics", Journal of Marketing Research, Vol. 38 No. 1, pp. 131-42.

Nunnally, J.C., 1981. Psychometric Theory. Tata McGraw-Hill, New Delhi.

Quinlan, S., Jaccard, J. and Blanton, H. (2006), "A decision theoretic and prototypeconceptualisation of possible selves: implications for the prediction of risk behaviour", Journal of Personality, Vol. 74, pp. 599-630.

Rogers, E.M. (1995), The Diffusion of Innovations, 4th ed.,The Free Press, New York, NY.

Sheppard, B.H., Hartwick, J. and Warshaw, P.R. (1988), “The theory of reasoned action: a metaanalysisof past research with recommendations for modifications and future research', Journal of Consumer Research, Vol. 15, pp. 325-43.

Taylor, S. and Todd, P. (1995), "Decomposition and crossover effects in the theory of plannedbehaviour: a study of consumer adoption intentions', International Journal of Research in Marketing, Vol. 12, pp. 137-55. 